\title{
Research Paper: The Effect of 6-gingerol on Growth Factors and Apoptosis Indices in Rats Exposed to Gold Nanoparticles
}

\author{
Ghasem Majdi Yazdi ${ }^{1}$ (D), Gholamhasan Vaezi ${ }^{*}$, Vida Hojati', Mohammad Mohammad-Zadeh²
}

1. Department of Biology, Faculty of Basic Sciences, Damghan Branch, Islamic Azad University, Damghan, Iran

2. Department of Physiology, School of Medicine, Mashhad University of Medical Sciences, Mashhad, Iran.

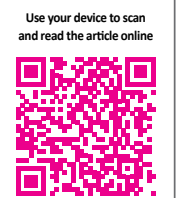

Cittation: Majdi Yazdi, Gh., Vaezi, Gh., Hojati, V., \& Mohammad-Zadeh, M. (2021). The Effect of 6-gingerol on Growth Factors and Apoptosis Indices in Rats Exposed to Gold Nanoparticles. Basic and Clinical Neuroscience, 12(3), 301-308. http:// dx.doi.org/10.32598/bcn.2021.357.1

i) $h$ ttp://dx.doi.org/10.32598/bcn.2021.357.1

Article info:

Received: 13 Oct 2019

First Revision: 03 Nov 2019

Accepted: 04 Apr 2020

Available Online: 01 May 2021

Keywords:

Nanoparticles, Hippocampus gingerol, Brain derived neurotrophic factor, Nerve growth factor

\section{AB S T RA C T}

Introduction: Research has shown that gold nanoparticles (AuNPs) can damage the physiological processes of brain tissue. Given the antioxidant properties of Gingerol (GING), this study aimed to determine the protective effect of 6-gingerol on hippocampal levels of Brain-Derived Neurotrophic Factor (BDNF), Nerve Growth Factor (NGF), DNA oxidative damage, and the amount of $\mathrm{Bax}$ and $\mathrm{Bcl} 2$ apoptosis indices of rats exposed to AuNPs.

Methods: A total of 42 male Wistar rats were divided into four groups: control (30 days 0.5 $\mathrm{mL}$ saline), AuNPs (one time injection of $0.5 \mathrm{~mL}$ AuNPs, $200 \mathrm{ppm}$ and $60 \mathrm{Nm}+30$ days 0.5 $\mathrm{mL}$ saline), AuNPs+GING 50 (one time injection of $0.5 \mathrm{~mL} \mathrm{AuNPs}, 200 \mathrm{ppm}$ and $60 \mathrm{Nm}+30$ days $0.5 \mathrm{~mL}$ density of gingerol $50 \mathrm{mg} / \mathrm{kg}$ ), and AuNPs+GING100 (one time injection of 0.5 $\mathrm{mL}$ AuNPs, $200 \mathrm{ppm}$ and $60 \mathrm{Nm}+30$ days $0.5 \mathrm{~mL}$ density of gingerol $100 \mathrm{mg} / \mathrm{kg}$ ). At the end of the treatment period, the hippocampal levels of NGF, BDNF, 8-hydroxy-desoxyguanosine (8-HOdG), and apoptotic indices of Bax and Bcl-2 were assessed with the ELISA method.

Results: Compared with the AuNPs group, hippocampal levels of BDNF, NGF, and Bcl-2 in rats in the AuNPs+GING 50 and AuNPs+GING 100 groups significantly increased dosedependently. However, the hippocampal levels of Bax and 8-HOdG significantly decreased dose-dependently $(\mathrm{P}<0.05)$.

Conclusion: According to obtained results, gingerol may improve hippocampal BDNF and NGF levels in rats exposed to AuNPs, probably by reducing apoptosis and oxidative DNA damage. 


\section{Highlights}

- Gingerol improves hippocampal BDNF and NGF levels in rats exposed to AuNPs.

- Gingerol reduces DNA oxidative damage of rats exposed to AuNPs.

- Gingerol apoptosis in hippocampal tissue of rats exposed to AuNPs.

\section{Plain Language Summary}

Today, the use of gold nanoparticles in cosmetics and medicine is very common. In addition to the beneficial effects of these nanoparticles, there are reports of their harms. These nanoparticles are said to damage the brain and produce active radicals. Ginger is known as an antioxidant. The aim of this study was to investigate whether ginger can affect brain-damaging factors and alter nerve growth factors. Based on the results of this study, it is suggested that ginger protects the brain from possible damage caused by gold nanoparticles and reduces cellular damage.

\section{Introduction}

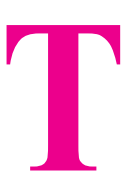

he development of nanotechnology has highlighted the investigation of nanoparticle effects on human health and the environment (Saeedi, Eslamifar, Khezri \& Maleki Dizaj, 2019). Gold nanoparticles (AuNPs) disrupt various physiological systems of the body, especially the nervous system. Nanoparticles impair cell function by altering the structure and permeability of cell membranes. Because of their small size, nanoparticles can cross the brain barrier and damage nerve cells, and disrupt brain functioning (Elahi, Kamali \& Baghersad, 2018). Research has shown that AuNPs damage DNA, disrupt the cell cycle and its proliferation, and ultimately cause apoptosis in human neural precursor cells (Söderstjerna, Johansson, Klefbohm \& Englund Johansson, 2013). AuNPs affect nerve cells by crossing the blood-brain barrier and increasing the free radicals, and activating the apoptosis pathway (Kang, Mackey \& El-Sayed, 2010). Numerous studies have suggested that AuNPs cause oxidative stress and inflammation by increasing the production of free radicals and disrupting the cells' antioxidant system (Jia et al., 2009; Tedesco, Doyle, Blasco, Redmond \& Sheehan, 2010).

Neurotrophins are a group of nerve growth factors with a protein structure that play a valuable role in protecting and shaping neurons in the central and peripheral nervous system besides the development of the nervous system. They also can differentiate stem cells into neurons. Neurotrophins include nerve growth factor, brain-derived neurotrophic factor, neurotrophin-3, and neurotrophin-4 (Chen, Sawa \& Mobley, 2018). It has also been shown that the highest activity of brain-derived neurotrophic factor is in the hippocampus and brain cortex (Chen et al., 2018).
In general, two pathways are involved in stimulating apoptosis. The outer pathway is activated by the stimulation of death membrane receptors, and the intrinsic or mitochondrial pathway is regulated by members of the Bcl2 family (Shirjang et al., 2020). It should be noted that the apoptosis process is regulated by $\mathrm{Bcl} 2$ family genes, including $\mathrm{Bcl}-2, \mathrm{Bcl}-\mathrm{Xl}, \mathrm{Bax}, \mathrm{Bad}$, and caspase family (Knight, Luedtke, Edwards, Taub \& Ge, 2019). Studies have shown that stress oxidative conditions can be a stimulus for initiating the apoptosis process. It has also been shown that an increase in Reactive Oxygen Species (ROS) by inducing stress oxidative and oxidative DNA damage can initiate the apoptosis process (Tang et al., 2019). Bcl2 has no antioxidant activity but may indirectly affect and increase intracellular antioxidant activity. Therefore, the increase in $\mathrm{Bcl} 2$ protein allows cells to better encounter free radicals, resulting in increased activity of antioxidant defense enzymes (Knight et al., 2019).

Ginger, as one of the herbs, has many antioxidant compounds. The pharmacological activity of ginger derives from its active components, including shogaols and gingerols. The most important gingerol is 6-gingerol which has the highest percentage among the gingerols (Srinivasan, 2017). 6-Gingerol attacks peroxyl radicals. The antioxidant activity of ginger compounds includes inhibition of free radicals, suppression of lipid peroxidation, and increased antioxidant molecules in cells (Khaki, Khaki, Hajhosseini, Golzar \& Ainehchi, 2014). Combinations in ginger rhizomes increase the activity of antioxidant enzymes (Baliga et al., 2011). The beneficial effects of ginger on stress oxidative markers in the cerebral cortex, cerebellum, hippocampus, and hypothalamus have also been studied in diabetic rats. The research suggests that ginger active compounds have neuroprotective effects in 
diabetic mice through enhancing and accelerating antioxidant defense mechanisms (Carretero et al., 2014).

Due to the growing trend of using herbs and antioxidant properties of gingerol, the present study aimed to determine the protective effect of 6-gingerol on the hippocampal levels of brain-derived neurotrophic factor, nerve growth factor, DNA oxidative damage and the level of BAX and Bcl apoptotic markers in rats exposed to AuNPs. Therefore, in the present study, we investigated the effect of 6-gingerol on growth factors and apoptosis indices in rats exposed to AuNPs.

\section{Methods}

\section{2-1. Experimental animals}

In this experimental study, mature male Wistar rats were used. A total of 42 rats with an average weight of $158 \pm 54$ $\mathrm{g}$ were kept at a temperature of $25 \pm 2^{\circ} \mathrm{C}$, relative humidity of $35 \pm 5 \%$, under 12 -h lightness and darkness period. The animals were housed in individual cages with woodchip bedding and free access to standard food and water.

\section{2-2. Synthesis and characterization of AuNPs}

AuNPs with a diameter of $60 \mathrm{~nm}$ were purchased from Sigma (Sigma-Aldrich, Germany) in powder form. Normal saline was used as a solution. A colloidal solution was prepared by ultrasonic centrifugation and then was injected into animals. The method of preparation of gingerol solution at concentrations of 50 and $100 \mathrm{mg} / \mathrm{kg}$ is as follows. Gingerol powder was purchased from Sigma (Sigma-Aldrich, Germany) and stored at $4^{\circ} \mathrm{C}$. The animal groups of AuNPs+GING 50 and AuNPs+GING 100 were prepared, respectively, by injecting $0.5 \mathrm{~mL}$ of 50 and 100 $\mathrm{mg} / \mathrm{kg}$ (normal saline as a vehicle) intraperitoneally.

\section{2-3. Experimental design}

The study rats were randomly divided into 4 groups ( $\mathrm{n}=6$ per group): the control group, AuNPs+vehicle group, and two experimental receiving AuNPs treated with gingerol (50 and $100 \mathrm{mg} / \mathrm{kg}$ ) (AuNPs+GING 50 and AuNPs+GING 100). The control group received $0.5 \mathrm{~mL}$ of saline intraperitoneally (every other day) for 30 days. In AuNPs+vehicle group animals, $0.5 \mathrm{~mL}$ colloid solution of AuNPs (Sigma-Aldrich, Germany) (200 ppm, $60 \mathrm{~nm}$ intraperitoneally) was administrated on day 0 . Then 10 days after receiving AuNPs, the rats were injected $0.5 \mathrm{~mL}$ normal saline as a vehicle every other day for 30 days. In AuNPs+GING 50 and AuNPs+GING 100 groups, the method used for the AuNPs+vehicle group was used except that the animals received gingerol $(0.5 \mathrm{~mL})$ with doses of 50 and $100 \mathrm{mg} / \mathrm{kg}$, respectively.

\section{2-4. Biochemical assay}

At the end of the 30-day treatment period, the rats were anesthetized with diethyl ether (Sigma Aldrich, Germany). Then, their brain tissue was extracted, and the hippocampal tissue was isolated according to the structural map of the rat brain. After washing the hippocampal tissue by saline solution with Tris buffer (Sigma-Aldrich, Germany), it was homogenized with buffered saline for 5 minutes with a homogenizer device (T25 Digital ULTRA-TURRAX, IKA, Germany) at 5000 rounds per minute. The homogenized solution was centrifuged by a refrigerated centrifuge at $5000 \mathrm{rpm}$ for 5 minutes (Z366, Hermle, Germany). To prevent the degradation of enzymes and proteins, all steps were performed at $4{ }^{\circ} \mathrm{C}$, and $0.5 \mathrm{MM}$ phenylmethylsulfonyl fluoride solution was used as a protease inhibitor (Sigma-Aldrich, Germany). The cytoplasm was employed to measure tissue level Brain-Derived Neurotrophic Factor (BDNF), Nerve Growth Factor (NGF), 8-HOdG, and apoptosis indices of Bax and Bcl2 through the ELISA method.

\section{2-5. Statistical analysis}

The obtained data were analyzed in SPSS v. 16. The assumption of normality of data frequency distribution was obtained through the Kolmogorov-Smirnov test $(\mathrm{P}>0.01)$. The effects of different concentrations of treatments were evaluated using 1-way ANOVA with the help of GraphPad Prism 5. The differences between the means were evaluated by Tukey's post hoc test with a minimum significance level of $\mathrm{P}<0.05$.

\section{Results}

Data analysis of this study showed that AuNPs administration decreased hippocampal levels of BDNF (Figure $1 \mathrm{~A})$ and NGF (Figure 1B) when compared to the control group $(\mathrm{P}<0.05)$. The hippocampal level of HOdG- 8 in rats of the AuNPs group increased significantly in comparison to the control group (Figure $1 \mathrm{C})(\mathrm{P}<0.05)$. In addition, intraperitoneal injection of gingerol $(50 \mathrm{mg} / \mathrm{kg}$ and $100 \mathrm{mg} / \mathrm{kg}$ ) to AuNPs+GING 50 and AuNPs+GING 100 groups, increased hippocampal levels of BDNF and NGF significantly in a dose-dependent manner. Also, the hippocampal level of 8-HOdG decreased significantly in a dose-dependent manner $(\mathrm{P}<0.05)$ (Figure 1).

Statistical analysis showed that the Bax level of the hippocampus increased after AuNPs administration, 

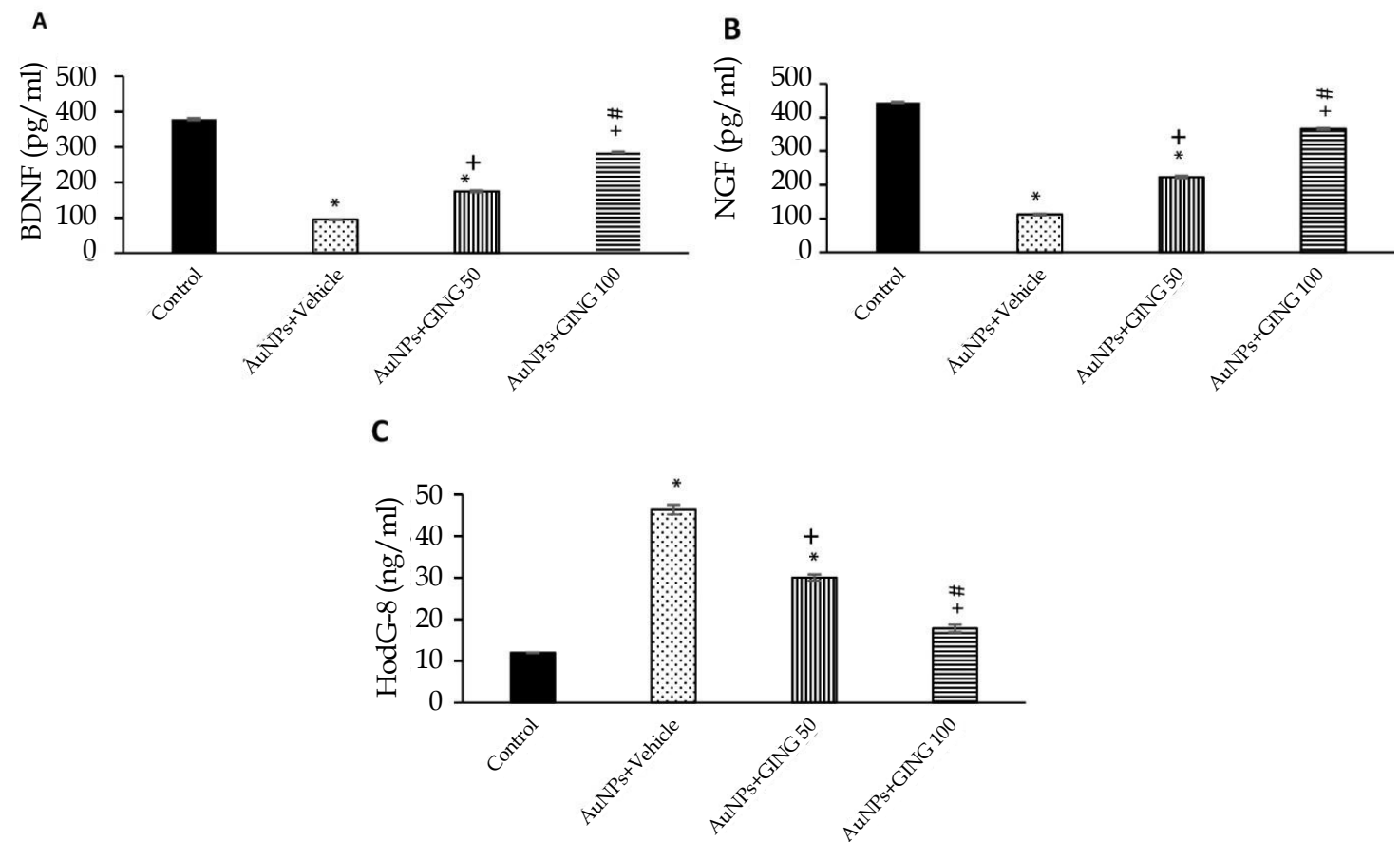

Figure 1. The efect of gold nanoparticles (AuNPs) and Gingerol (50 and $100 \mathrm{mg} / \mathrm{kg}$ )

NEUR SCIENCE

A: Hippocampal levels of Brain-Derived Neurotrophic Factor (BDNF); B: Nerve Growth Factor (NGF); and C: 8-HOdG compared to the control group $(\mathrm{n}=6)$.

${ }^{\star} \mathrm{P}<0.05$ when compared to the control group; ${ }^{+} \mathrm{P}<0.05$ when compared to the AuNPs; ${ }^{*} \mathrm{P}<0.05$ when compared to AuNPs+GING 50 group by Tukey's post hoc test.

but gingerol at doses of 50 and $100 \mathrm{mg} / \mathrm{kg}$ decreased it significantly. However, this decrease did not reach the level of the control group (Figure 2). Also, AuNPs administration decreased $\mathrm{Bcl} 2$ level in the hippocampus, and gingerol at doses of 50 and $100 \mathrm{mg} / \mathrm{kg}$ increased it significantly in a dose-dependent manner (Figure 2).

A

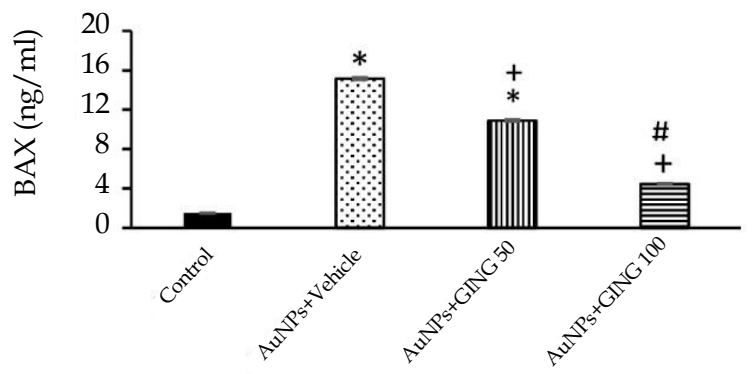

\section{Discussion}

Current findings demonstrated the protective effect of 6-gingerol on hippocampal levels of brain-derived neurotrophic factor, neuronal growth factor, DNA oxidative damage, and apoptosis indices of Bax and BcL2 in rats exposed to AuNPs. It means that gingerol prevented or
B

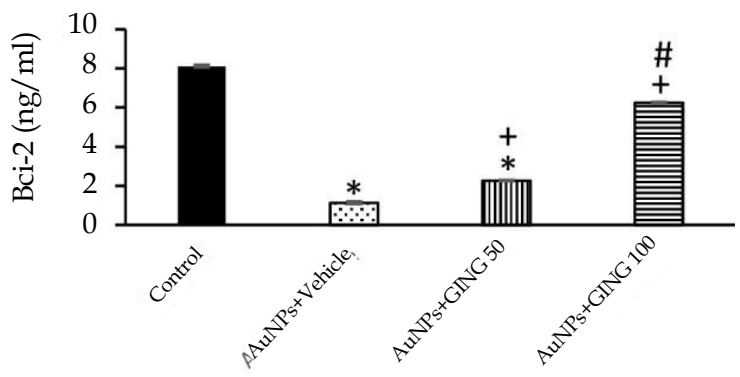

Figure 2. The effect of gold nanoparticles (AuNPs) and Gingerol (50 and $100 \mathrm{mg} / \mathrm{kg}$ )

NEUR:SCIENCE

A: Hippocampal levels of Bax; and B: BcL2.

${ }^{*} \mathrm{P}<0.05$ when compared to the control group; ${ }^{+} \mathrm{P}<0.05$ when compared to the AuNPs; $\mathrm{P}<0.05$ when compared to the AuNPs+GING 50 group by Tukey's post hoc test. 
decreased the apoptotic effects of AuNPs and protects or improves brain function by increasing growth factors.

The results showed that intraperitoneal injection of AuNPs reduced hippocampal Bcl2 levels and increased Bax. In other words, AuNPs could induce apoptosis in hippocampal tissue. AuNPs have been reported to induce apoptosis in melanoma B16F10 cancer cells (Chang et al., 2008). Another study showed that AuNPs induce apoptosis in HL7702 cells by activating the mitochondrial pathway of apoptosis and reducing antioxidant capacity, and reducing glutathione (Chang et al., 2008; Gao, Xu, Ji \& Tang, 2011). The researchers showed that AuNPs break down the double-stranded DNA structure by penetrating the cell nucleus. They also inhibit tumor growth by inhibiting cytokines and inducing apoptosis in cancer cells (Kang et al., 2010). Another study showed that AuNPs induce apoptosis by inhibiting Bcl2 and increasing toxicity in the HeLa cancer cell pathway (Daduang et al., 2015).

It has been shown that AuNPs induce apoptosis and consequently, neuronal death by increasing caspase-3 and Hsp-70 proteins (Siddiqi, Abdelhalim, El-Ansary, Alhomida \& Ong, 2012). The present study results showed that hippocampal levels of NGF and BDNF decreased in AuNPs-treated rats. After crossing the blood-brain barrier and inhibiting gene expression, AuNPs reduce the number of neurotrophins secreted in the central nervous system and impair spatial memory functioning in the brain (Bonoiu et al., 2011). AuNPs disrupt the biosynthesis of neurotrophins by reducing the antioxidant capacity of neurons, especially glutathione peroxidase. AuNPs also decrease neurotransmitters such as dopamine and serotonin due to impaired intracellular organelle function, as demonstrated by behavioral tests (Siddiqi et al., 2012). In this study, we found that hippocampal levels of 8-HOdG increased in rats receiving AuNPs. Research results showed that AuNPs cause DNA damage through a significant increase in ROS, decrease in antioxidant enzyme activity, increase in inflammatory factors such as interleukin-6, and increase in plasma nitric oxide synthesis. These findings have been confirmed by increasing levels of $8-\mathrm{HOdG}$ in urine as a biological index of DNA damage (Shrivastava, Kushwaha, Bhutia \& Flora, 2016). Research results showed that AuNPs could increase 8-HOdG levels, indicating DNA damage (Siddiqi et al., 2012). Researchers have shown that cation AuNPs have toxic effects on cells, and these effects are exacerbated by increased ROS production and DNA oxidative damage (Chompoosor et al., 2010). Another study showed that AuNPs cause oxidative stress and DNA damage in lung fibroblast cells under in vitro condition (Li et al., 2008).

The toxicity effects of AuNPs with a size of $4.1 \mathrm{~nm}$ were also found to be directly related to decreased potency of the antioxidant defense system, increased intracellular ROS production, and oxidative DNA damage (Pan et al., 2009).

The study results showed that treatment of rats receiving AuNPs with 50 and $100 \mathrm{mg} / \mathrm{kg}$ 6-gingerol dose-dependently increased hippocampal BDNF and NGF levels. Gingerol also reduced hippocampal 8-HOdG levels and improved apoptotic indices. Ginger has been shown to have antioxidant and anti-inflammatory properties because of 6-gingerol. On the other hand, flavonoid compounds such as 6-gingerol have been reported to have potent antioxidant properties and prevent body cell oxidative stress (Nwozo, Osunmadewa \& Oyinloye, 2014). Ginger extract has been reported to reduce the adverse effects of free radicals on hepatocellular injury by having antioxidant properties and reducing ROS levels.

On the other hand, the use of ginger because of its flavonoid compounds enhances the activity of antioxidant enzymes such as glutathione S-transferases in the liver, lung, and intestine (Sakr, 2007). Gingerols in ginger contain antioxidant chemicals and eliminate free radicals and active metabolites in the body. This reaction reduces oxidative DNA damage and repair damaged DNA (Mohamed, El-Nahas, El-Sayed \& Ashry, 2016). Animal studies aimed at investigating the effect of ginger extract on the pathways of liver injury suggest that the active constituents of mojo in ginger enhance the antioxidant defense system (Nwozo et al., 2014).

Ginger has been reported to decrease lipid peroxidation, increase intracellular antioxidant capacity, and inhibit free radicals (Ajith, Hema \& Aswathy, 2007). Recent studies show that the compounds in the ginger rhizome significantly enhance cognitive functioning in the brain of healthy mice and those with cognitive impairments such as Alzheimer's. Ginger has also been shown to improve cognitive function by activating the ERK/CREB pathway induced by increased hippocampal NGF levels (Lim et al., 2014).

Research shows that ginger and its compounds, such as 6-gingerol, have neuroprotective properties and effectively improve age-related neurological disorders by preserving the physiological conditions of neurons, increasing neurotransmitter secretion, and reducing death signals (Choi, Kim, Jeong \& Oh, 2018). Gingerol has been report- 
ed to protect the brain against organophosphorus-induced oxidative stress, inflammation, and apoptosis (Abolaji et al., 2017). The results showed that the active constituents in the ginger rhizome have neurogenic activity by activating the $\mathrm{MEK} / \mathrm{ERK} 1 / 2$ and $\mathrm{PI} 3 \mathrm{~K} / \mathrm{AKT}$ signaling pathways in PC-12 cells. 6-Shogaol is another ginger compound that can act as NGF and mimic its physiological behavior (Seow, Hong, Lee, Malek \& Sabaratnam, 2017).

This study showed that 6-gingerol could inhibit Bax and increase $\mathrm{Bcl} 2$ in AuNPs recipient rats. Consistent with these results, the researchers showed that 6-gingerol has a protective effect on renal cells in gentamicininduced kidney damage. 6-Gingerol has also been shown to inhibit apoptosis in damaged kidney cells by inhibiting caspase-3 and Hsp 47 proteins (Hegazy, Mosaed, Elshafey \& Bayomy, 2016). There are conflicting reports on the apoptotic effects of 6-gingerol. As an example, researchers have shown that 6-gingerol, as a natural antioxidant through DNA fragmentation and $\mathrm{Bcl} 2$ inhibition cause HL-60 cell death. These results indicate that inhibition of $\mathrm{Bcl} 2$ expression in HL-60 cells induces apoptosis (Wang, Chen, Lee \& Yang, 2003). In general, It may be the dosage of 6-gingerol is the most important factor that can have inductive or inhibitory effects on apoptosis. The study's limitations are the insufficient facilities for conducting behavioral studies that could supplement the results. The present study was implemented under in vivo condition, so it is recommended to be performed under in vitro condition to understand the results better and find out the molecular mechanisms of gingerol.

\section{Conclusion}

This study shows that gingerol as a natural antioxidant reduces DNA oxidative damage and apoptosis in hippocampal tissue of rats exposed to AuNPs. It also improves hippocampal BDNF and NGF levels in rats exposed to AuNPs. This outcome may be due to the protective effect of gingerol in the brain tissue.

\section{Ethical Considerations}

\section{Compliance with ethical guidelines}

All tests were executed according to the guidelines for the care and use of laboratory animals (National Institutes of Health Newsletter No. 80-23, revised 1996). Each animal was used only once. Rats got familiar with their new environment before starting the experimental process.

\section{Funding}

This research was extracted from the $\mathrm{PhD}$. dissertation of the first author at the Department of Physiology, School of Basic Sciences, Islamic Azad University of Damghan, Dameghan City.

Authors' contributions

All authors equally contributed to preparing this article.

\section{Conflict of interest}

The authors declared no conflict of interest.

\section{References}

Abolaji, A. O., Ojo, M., Afolabi, T. T., Arowoogun, M. D., Nwawolor, D., \& Farombi, E. O. (2017). Protective properties of 6-gingerol-rich fraction from Zingiber officinale (Ginger) on chlorpyrifos-induced oxidative damage and inflammation in the brain, ovary and uterus of rats. Chemico-Biological Interactions, 270, 15-23. [DOI:10.1016/j.cbi.2017.03.017] [PMID]

Ajith, T. A., Hema, U., \& Aswathy, M. S. (2007). Zingiber officinale Roscoe prevents acetaminophen-induced acute hepatotoxicity by enhancing hepatic antioxidant status. Food and Chemical Toxicology, 45(11), 2267-72. [DOI:10.1016/j. fct.2007.06.001] [PMID]

Baliga, M. Sh., Haniadka, R., Pereira, M. M., D'Souza, J. J., Pallaty, P. L., \& Bhat, H. P., et al. (2011). Update on the chemopreventive effects of ginger and its phytochemicals. Critical Reviews in Food Science and Nutrition, 51(6), 499-523. [DOI:10.1080/10408391003698669] [PMID]

Bonoiu, A. C., Bergey, E. J., Ding, H., Hu, R., Kumar, R., \& Yong, K. T., et al. (2011). Gold nanorod--siRNA induces efficient in vivo gene silencing in the rat hippocampus. Nanomedicine, 6(4), 617-30. [DOI:10.2217/nnm.11.20] [PMID] [PMCID]

Carretero, A., León, Z., García-Cañaveras, J. C., Zaragoza, Á., Gómez-Lechón, M. J., \& Donato, M. T., et al. (2014). In vitro/ in vivo screening of oxidative homeostasis and damage to DNA, protein, and lipids using UPLC/MS-MS. Analytical and Bioanalytical Chemistry, 406(22), 5465-76. [DOI:10.1007/ s00216-014-7983-5] [PMID]

Chang, M. Y., Shiau, A. L., Chen, Y. H., Chang, C. J., Chen, H. H. W., \& Wu, C. L. (2008). Increased apoptotic potential and dose-enhancing effect of gold nanoparticles in combination with single-dose clinical electron beams on tumor-bearing mice. Cancer Science, 99(7), 1479-84. [DOI:10.1111/j.13497006.2008.00827.x] [PMID]

Chen, X. Q., Sawa, M., \& Mobley, W. C. (2018). Dysregulation of neurotrophin signaling in the pathogenesis of Alzheimer disease and of Alzheimer disease in Down syndrome. Free Radical Biology and Medicine, 114, 52-61. [DOI:10.1016/j.freeradbiomed.2017.10.341] [PMID] [PMCID] 
Choi, J. G., Kim, S. Y., Jeong, M., \& Oh, M. S. (2018). Pharmacotherapeutic potential of ginger and its compounds in agerelated neurological disorders. Pharmacology $\mathcal{E}$ Therapeutics, 182, 56-69. [DOI:10.1016/j.pharmthera.2017.08.010] [PMID]

Chompoosor, A., Saha, K., Ghosh, P. S., Macarthy, D. J., Miranda, O. R., \& Zhu, Z. J., et al. (2010). The role of surface functionality on acute cytotoxicity, ROS generation and DNA damage by cationic gold nanoparticles. Small, 6(20), 2246-9. [DOI:10.1002/smll.201000463] [PMID] [PMCID]

Daduang, J., Palasap, A., Daduang, S., Boonsiri, P., Suwannalert, P., \& Limpaiboon, T. (2015). Gallic acid enhancement of gold nanoparticle anticancer activity in cervical cancer cells. Asian Pacific Journal of Cancer Prevention, 16(1), 169-74. [DOI:10.7314/ APJCP.2015.16.1.169] [PMID]

Elahi, N., Kamali, M., \& Baghersad, M. H. (2018). Recent biomedical applications of gold nanoparticles: A review. Talanta, 184, 537-56. [DOI:10.1016/j.talanta.2018.02.088] [PMID]

Gao, W., Xu, K., Ji, L., \& Tang, B. (2011). Effect of gold nanoparticles on glutathione depletion-induced hydrogen peroxide generation and apoptosis in HL7702 cells. Toxicology Letters, 205(1), 86-95. [DOI:10.1016/j.toxlet.2011.05.1018] [PMID]

Hegazy, A. M. S., Mosaed, M. M., Elshafey, S. H., \& Bayomy, N. A. (2016). 6-gingerol ameliorates gentamicin induced renal cortex oxidative stress and apoptosis in adult male albino rats. Tissue and Cell, 48(3), 208-16. [DOI:10.1016/j.tice.2016.03.006] [PMID]

Jia, H. Y., Liu, Y., Zhang, X. J., Han, L., Du, L. B., \& Tian, Q., et al. (2009). Potential oxidative stress of gold nanoparticles by induced-NO releasing in serum. Journal of the American Chemical Society, 131(1), 40-1. [DOI:10.1021/ja808033w] [PMID]

Kang, B., Mackey, M. A., \& El-Sayed, M. A. (2010). Nuclear targeting of gold nanoparticles in cancer cells induces DNA damage, causing cytokinesis arrest and apoptosis. Journal of the American Chemical Society, 132(5), 1517-19. [DOI:10.1021/ ja9102698] [PMID]

Khaki, A., Khaki, A. A., Hajhosseini, L., Golzar, F. S., \& Ainehchi, N. (2014). The anti-oxidant effects of ginger and cinnamon on spermatogenesis dys-function of diabetes rats. African Journal of Traditional, Complementary, and Alternative Medicines, 11(4), 1-8. [DOI:10.4314/ajtcam.v11i4.1] [PMID] [PMCID]

Knight, T., Luedtke, D., Edwards, H., Taub, J. W., \& Ge, Y. (2019). A delicate balance: The BCL-2 family and its role in apoptosis, oncogenesis, and cancer therapeutics. Biochemical Pharmacology, 162, 250-61. [DOI:10.1016/j.bcp.2019.01.015] [PMID]

Li, J. J., Zou, L., Hartono, D., Ong, C. N., Bay, B. H., \& Lanry Yung, L. Y. (2008). Gold nanoparticles induce oxidative damage in lung fibroblasts in vitro. Advanced Materials, 20(1), 138-42. [DOI:10.1002/adma.200701853]

Lim, S., Moon, M., Oh, H., Kim, H. G., Kim, S. Y., \& Oh, M. S (2014). Ginger improves cognitive function via NGF-induced ERK/CREB activation in the hippocampus of the mouse. The Journal of Nutritional Biochemistry, 25(10), 1058-65. [DOI:10.1016/j.jnutbio.2014.05.009] [PMID]

Mohamed, O. I., El-Nahas, A. F., El-Sayed, Y. S., \& Ashry, K. M (2016). Ginger extract modulates Pb-induced hepatic oxidative stress and expression of antioxidant gene transcripts in rat liver. Pharmaceutical Biology, 54(7), 1164-72. [DOI:10.3109/ 13880209.2015.1057651] [PMID]
Nwozo, S. O., Osunmadewa, D. A., \& Oyinloye, B. E. (2014) Anti-fatty liver effects of oils from Zingiber officinale and Curcuma longa on ethanol-induced fatty liver in rats. Journal of Integrative Medicine, 12(1), 59-65. [DOI:10.1016/S20954964(14)60006-6]

Pan, Y., Leifert, A., Ruau, D., Neuss, S., Bornemann, J., \& Schmid, G., et al. (2009). Gold nanoparticles of diameter $1.4 \mathrm{~nm}$ trigger necrosis by oxidative stress and mitochondrial damage. Small, 5(18), 2067-76. [DOI:10.1002/smll.200900466] [PMID]

Saeedi, M., Eslamifar, M., Khezri, Kh., \& Maleki Dizaj, S. (2019). Applications of nanotechnology in drug delivery to the central nervous system. Biomedicine \& Pharmacotherapy, 111, 666-75. [DOI:10.1016/j.biopha.2018.12.133] [PMID]

Sakr, S. A. (2007). Ameliorative effect of ginger (Zingiber officinale) on mancozeb fungicide induced liver injury in albino rats. Australian Journal of Basic and Applied Sciences, 1(4), 650-6. https://www.researchgate.net/publication/266218559

Seow, S. L. S., Hong, S. L., Lee, G. S., Malek, S. N. A., \& Sabaratnam, V. (2017). 6-shogaol, a neuroactive compound of ginger (jahe gajah) induced neuritogenic activity via NGF responsive pathways in PC-12 cells. BMC Complementary and Alternative Medicine, 17(1), 334. [DOI:10.1186/s12906-017-1837-6] [PMID] [PMCID]

Shirjang, S., Mansoori, B., Asghari, S., Duijf, P. H. G., Mohammadi, A., \& Gjerstorff, M., et al. (2020). Corrigendum to "MicroRNAs in cancer cell death pathways: Apoptosis and necroptosis" [Free Radic. Biol. Med. 139 (2019) 1-15]. Free Radical Biology and Medicine, 146, 402. [DOI:10.1016/j.freeradbiomed.2019.06.014]

Shrivastava, R., Kushwaha, P., Bhutia, Y. C., \& Flora, S. J. S. (2016). Oxidative stress following exposure to silver and gold nanoparticles in mice. Toxicology and Industrial Health, 32(8), 1391-404. [DOI:10.1177/0748233714562623] [PMID]

Siddiqi, N. J., Abdelhalim, M. A. K., El-Ansary, A. K., Alhomida, A. S., \& Ong, W. Y. (2012). Identification of potential biomarkers of gold nanoparticle toxicity in rat brains. Journal of Neuroinflammation, 9, 123. [DOI:10.1186/1742-2094-9-123] [PMID] [PMCID]

Söderstjerna, E., Johansson, F., Klefbohm, B., \& Englund Johansson, U. (2013). Gold- and silver nanoparticles affect the growth characteristics of human embryonic neural precursor cells. PLoS One, 8(3), e58211. [DOI:10.1371/journal.pone.0058211] [PMID] [PMCID]

Srinivasan, K. (2017). Ginger rhizomes (Zingiber officinale): A spice with multiple health beneficial potentials. PharmaNutrition, 5(1), 18-28. [DOI:10.1016/j.phanu.2017.01.001]

Tang, J. Y., Ou-Yang, F., Hou, M. F., Huang, H. W., Wang, H. R., \& Li, K. T., et al. (2019). Oxidative stress-modulating drugs have preferential anticancer effects - involving the regulation of apoptosis, DNA damage, endoplasmic reticulum stress, autophagy, metabolism, and migration. Seminars in Cancer Biology, 58, 109-17. [DOI:10.1016/j.semcancer.2018.08.010] [PMID]

Tedesco, S., Doyle, H., Blasco, J., Redmond, G., \& Sheehan D. (2010). Oxidative stress and toxicity of gold nanoparticles in Mytilus edulis. Aquatic Toxicology, 100(2), 178-86. [DOI:10.1016/j.aquatox.2010.03.001] [PMID]

Wang, C. C., Chen, L. G., Lee, L. T., \& Yang, L. L. (2003). Effects of 6-gingerol, an antioxidant from ginger, on inducing apoptosis in human leukemic HL-60 cells. In Vivo, 17(6), 641-5. [PMID] 
This Page Intentionally Left Blank 